\title{
CAPITULO 41
}

\section{EDUCAÇÃO EM SAÚDE COMO FERRAMENTA PARA PROMOÇÃO DOS CUIDADOS AO RN: RELATO DE EXPERIÊNCIA}

\section{DOI 10.4322/978-65-995353-2-1.c41}

Amanda Ferreira de Magalhães Santos- Universidade Regional do Cariri- Iguatu, Ceará, Brasil.

Amanda Maria Chaves Barros- Universidade Regional do Cariri- Iguatu, Ceará, Brasil. Cinthia da Silva Nascimento Vieira- Universidade Regional do Cariri- Iguatu, Ceará, Brasil. John Herbert da Silva Brito- Universidade Regional do Cariri- Iguatu, Ceará, Brasil. Samuel Carlos Tomaz- Universidade Regional do Cariri- Iguatu, Ceará, Brasil. Virna Souza- Universidade Regional do Cariri- Iguatu, Ceará, Brasil. Samyra Paula Lustoza Xavier- Universidade Regional do Cariri- Iguatu, Ceará, Brasil.

\section{RESUMO}

A enfermagem objetiva juntar-se à mãe para garantir um melhor cuidado ao Recém-Nascido através da educação em saúde. Justificou-se apresentar a necessidade de informar às mães sobre os cuidados necessários para o Recém-Nascido. Objetivou-se relatar uma ação de educação em saúde às gestantes sobre os principais cuidados com seus recém-nascidos. A ação foi realizada na Estratégia Saúde da Família no ano de 2019, em Iguatu - CE, por acadêmicos do curso de bacharel em enfermagem. A ação teve abordagem qualitativa, onde cada discente discutiu com os ouvintes. O tema abordado foi: Os Principais Cuidados ao RN. A ação teve por finalidade instigar a curiosidade, participação e busca pelo conhecimento do público. Participaram do momento 4 gestantes e um homem. Foi realizado um círculo de conversa buscando a dinamização, o contato e entrosamento entre participantes. Concluiu-se que a visita trouxe enriquecimento técnico e potencializou o papel educativo da enfermagem.

Palavras-chaves: Educação em Saúde; Saúde da Criança; Estratégia Saúde da Família; Enfermagem Familiar; Saúde do Lactente.

Área Temática: Ciências da Saúde

E-mail do autor para correspondência: amanda.magalhaes@urca.br

\section{INTRODUÇÃO}

A educação em saúde é um campo que une a área da educação e da saúde com o intuito de trazer conhecimento sobre diferentes assuntos, permite que a população tenha acesso à ciência, o que, por conseguinte, dá maior autonomia e emancipação aos indivíduos que terão como responsabilidade o seu autocuidado, o da sua família e da sua comunidade (ARAÚJO; RODRIGUES; PACHECO, 2015).

E - book Tripé do Ensino Superior: Ensino, Pesquisa e Extensão 
Nas ações para promoção da saúde da criança, a educação em saúde é uma estratégia que deve ser oferecida nas maternidades e demais unidades de saúde para garantir um melhor cuidado e ajudar a diminuir a taxa de mortalidade neonatal. Sabe-se que o período neonatal é o momento mais sensível devido à imaturidade dos sistemas em geral, o que requer cuidados específicos com o Recém-Nascido (RN) (GOMES et al., 2015).

Nesse cenário, destaca-se a equipe de enfermagem que tem como objetivo juntar-se à mãe e incentivar para garantir um melhor cuidado ao $\mathrm{RN}$, o que favorece e promove o seu crescimento e desenvolvimento de forma saudável. A equipe profissional deve orientar a mãe levando em consideração os cuidados mais simples, como também os mais específicos, os quais contemplam temas diversos, como aqueles ligados à higiene tanto da mãe como do bebê, a sua alimentação, vacinações, dentre outros (ARAÚJO; RODRIGUES; PACHECO, 2015).

Ressalta-se também a inclusão do pai nas ações regulares de educação em saúde que acontecem dentro das Unidades Básicas de Saúde, visto que a gravidez sempre foi tratada como experiência unicamente feminina, mas que as divisões antes pré-estabelecidas como sendo unicamente de um sexo ou de outro estão em constante mudança, sendo hoje importantíssima a participação do pai em todo o decorrer da gestação (FERREIRA et al., 2014).

É de extrema importância que os alunos desenvolvam, durante a formação em saúde, a criatividade necessária para executar ações de saúde com públicos vulneráveis, visto que a falta de informação pode ocasionar uma internação hospitalar ou até morte, quando se trata do RN. É necessário repassar que a utilização de métodos e práticas empíricas no tratamento de doenças ou em situações de urgência e emergência não surtem resultados que contribuem para a evolução do paciente, devendo o profissional promover promoção, prevenção e cuidados baseados em evidências científicas (ARAÚJO; RODRIGUES; PACHECO, 2015).

Mediante o exposto, vislumbra-se a necessidade de reafirmar ao profissional de saúde a importância do seu trabalho enquanto educador em saúde, bem como destacar que essas ações são fundamentais para a promoção do cuidado materno, adequadas às demandas do RN. Nesse sentido, objetivou-se relatar a experiência vivida em uma ação de educação em saúde às gestantes sobre os principais cuidados com seus recém-nascidos.

\section{MÉTODO}

Trata-se de um estudo descritivo do tipo relato de experiência realizado por discentes do sexto semestre do curso de graduação em enfermagem da Universidade Regional do Cariri - Unidade Descentralizada de Iguatu, durante a disciplina de Educação em Saúde. A ação foi monitorada por uma aluna do nono semestre, estagiária da respectiva Unidade Básica de Saúde 
durante a disciplina do Supervisionado I, e pela professora docente de ambas as disciplinas. A atividade teve como tema geral Os Principais Cuidados ao Recém-Nascido.

A ação foi realizada em outubro de 2019, em uma unidade da Estratégia Saúde da Família (ESF), localizada em um município da região Centro-Sul do Estado do Ceará. A escolha dessa unidade justificou-se pelo acesso facilitado dos discentes em decorrência do vínculo institucional universidade-ESF, bem como por esse ser um território com muitas vulnerabilidades em saúde.

Essa ação foi facilitada pelos Agentes Comunitários de Saúde, que a pedido da aluna do nono semestre realizaram a busca ativa das gestantes. Foi realizada uma reunião onde foram decididos os temas abordados (imunização, amamentação, engasgo, higienização, vestimenta e agasalhamento e posicionamento correto durante o sono) e a metodologia de ensino, a qual se deu a partir de uma exposição dialogada com apresentação de cartazes/imagens ilustrativas e uso de bonecas para simular as dinâmicas de cuidados de acordo com o tema em questão.

Todo o desenvolvimento da ação foi monitorado pela aluna do nono semestre e pela professora orientadora que contribuíram com a adição de saberes.

\section{RESULTADOS E DISCUSSÃO}

Durante a ação, foi realizado um círculo de conversa em um espaço reservado na unidade de saúde com intuito de dinamizar, instigar e facilitar o vínculo entre discentesparticipantes da ação, para que o momento fosse de partilha e aprendizado para ambas as partes.

$\mathrm{Na}$ ocasião, estiveram presentes quatro gestantes e um pai que aceitou participar do momento enquanto sua esposa, gestante, estava em atendimento médico na unidade. A presença paterna durante a ação surpreendeu a toda a equipe, principalmente quando o pai relatou ser presente durante as consultas de pré-natal e dar suporte a sua companheira durante todas as mudanças físicas e emocionais pelas quais ela passou. Tal fato merece destaque, pois contrapõe as experiências vivenciadas pelos outros discentes que atuam na unidade, bem como pelo relato da professora que afirmava ver pouca presença dos homens no pré-natal e na puericultura.

O papel do pai durante o desenvolvimento da criança tem sua importância destacada, visto que tal envolvimento no processo de criação resultará em um futuro adulto que apresentará maior felicidade. $\mathrm{O}$ acompanhamento paterno em consultas ou grupos educativos durante a gestação reflete na relação conjugal, que poderá apresentar maior compreensão entre o casal quanto ao período gravídico, bem como na relação pai-filho, pelo fato de que as lembranças durante a vida pré-natal são retidas e ajudam no vínculo que será construído entre pai e bebê (FERREIRA et al., 2014).

E - book Tripé do Ensino Superior: Ensino, Pesquisa e Extensão 
O primeiro tema abordado foi a imunização do $\mathrm{RN}$, com destaque às vacinas $\mathrm{BCG}$ e Hepatite B, pois são as primeiras a serem aplicadas. Foi explanada que a principal maneira de evitar a tuberculose em crianças é por meio da BCG, vacina esta responsável por deixar a cicatriz na região do músculo deltoide do braço direito, no nível da inserção inferior deste músculo, o que facilita a identificação da cicatriz. As dúvidas envolvendo a formação da pápula foram sanadas, assim como os cuidados para com ela. Já acerca da vacina contra Hepatite B, foi ressaltada a aplicação de compressas frias para o alívio da dor.

A ESF apresenta uma grande relevância no que se refere às ações humanizadas de saúde, o próprio Ministério da Saúde a considera um avanço do Sistema Único de Saúde. A ela competem as ações de imunização e isso a torna algo acessível à população, o que acarreta em grandes contribuições positivas, principalmente para as crianças. Para as estratégias de imunização infantil, é imprescindível a oferta de informações aos pais, eles devem ficar cientes da sua importância, dos seus efeitos, das futuras aplicações e das suas demais contribuições para a diminuição da mortalidade infantil (HOFFMANN, 2009).

O próximo assunto debatido na ação foi a amamentação e os seus benefícios. Observouse que os participantes entendiam como um ato de benefício somente para o bebê e sem acréscimo algum para a mãe. Através de uma boneca, foi demonstrada a forma correta da pega durante a amamentação, bem como as melhores posições para o bebê. Houve a resolução das dúvidas e de possíveis erros que normalmente ocorrem durante o processo de amamentação, de forma a evitar que o momento se transforme em uma situação de dor, ansiedade e espera pelo fim.

Antunes et al. (2008) trazem que os benefícios da amamentação não atingem a criança apenas quando bebê, tendo vantagens também para a saúde futura do indivíduo. Mães que amamentam seus filhos até os seis meses percebem diante de exames uma boa visão do filho, menores taxas de infecções parasitárias se comparado a uma criança que não foi amamentada e na vida adulta menos riscos de doenças cardiovasculares, redução do surgimento de diabetes e metade do risco de desenvolvimento de quaisquer disfunções neurológicas.

Em seguida, abordou-se sobre o engasgo. Para aquele público, o engasgo era caracterizado como a presença de um corpo estranho nas vias aéreas que tomou um "caminho errado" durante o ato de engolir; consequentemente isso interfere a passagem de ar para os pulmões, causando a asfixia. Após ouvir o conceito do público e reorientá-los sobre sua correta definição, a equipe seguiu apresentando a Manobra de Heimlich de forma prática em uma boneca. Ao final da explicação da manobra, uma das gestantes relatou um episódio de engasgo com seu filho, a qual durante um momento de desespero o reflexo a fez lançar a criança para o 
alto, com o objetivo de desobstruir as vias aéreas. Depois de toda a explicação, resolução de dúvidas e escuta dos relatos sobre o assunto, todos praticaram a técnica utilizando a boneca.

Para que a mãe possa atuar com calma e segurança diante de situações como essas, é necessário não apenas o conhecimento teórico, é imprescindível o treinamento (com um profissional atuante da área) para domínio efetivo da prática. Esse treinamento pode estar sendo realizado pela mãe com uma boneca que tenha o tamanho aproximado de um bebê recémnascido, e possibilita a identificação da localização anatômica para a manobra. Quanto mais vezes a mãe treina a prática simulada, mais ela sentirá segurança para enfrentar a situação quando for real (FARINHA; RIVAS; SOCCOL, 2020).

Ao abordar sobre a higienização, foi demonstrada a melhor forma de realizar a limpeza do $\mathrm{RN}$, incluindo o coto umbilical e a região íntima com o auxílio da boneca novamente. $\mathrm{O}$ público não apresentou dúvidas quanto à limpeza do coto umbilical. Uma das mães relatou achar a higienização íntima feminina mais fácil, porém observou-se que ela possuía somente filhas e não tinha experiência com a higienização masculina; o contrário também foi observado em outra gestante que possuía somente filhos do sexo masculino. A mesma gestante reafirmou a importância de puxar o prepúcio para a remoção e prevenção do acúmulo de esmegma no pênis.

Orientar quanto à higienização corporal adequada para o RN é de extrema relevância, pois a pele do bebê é extremamente sensível e fina, o que necessita de uma atenção redobrada quanto ao seu cuidado. Sendo assim, é aconselhável que a higienização do RN seja feita com líquidos, sem sabão, suaves, sem cheiro, com pH neutro de uma forma que não modifique o tecido subcutâneo, nem irrite a pele ou seus olhos. O cordão umbilical merece também uma atenção redobrada, uma vez que pode ser uma importante entrada de micro-organismos. Sua limpeza deve ser diária, com água e sabão, com enxague e secagem adequada, aplicado ainda o álcool a 70\% entre as trocas de fralda. É importante não cobrir a região umbilical com nenhum tipo de objeto nem colocar nada além do recomendado (AMADOR, 2014).

Na sequência o grupo explanou sobre a melhor forma de higienização da vestimenta do RN. Recomendou-se o uso de sabão de coco ou neutro devido à baixa quantidade de ácidos e perfumes na sua composição, o que diminui os riscos de alergias. Também foi aconselhado evitar o uso de amaciantes, alvejantes, sabão em pó comum ou removedor de manchas. Foi aconselhado não lavar junto com as roupas de adulto para evitar o contato com secreções indesejáveis, deixar a roupa secar e logo em seguida passar o ferro quente para evitar a proliferação de micro-organismos.

E - book Tripé do Ensino Superior: Ensino, Pesquisa e Extensão 
Vestir as roupas adequadas de acordo com o clima foi outra questão também debatida durante o momento. Foi ressaltada a utilização de roupas de cores mais claras e leves para os dias mais quentes e nos períodos de frio realizar um bom agasalhamento no RN para evitar a hipotermia. As mães comentaram que possuíam tal conhecimento, porém discordaram quanto ao agasalhamento, devido o clima quente na maior parte do ano. Percebeu-se que as mães obtiveram esse conhecimento de forma empírica, adquirido na comunidade e que passava de geração em geração.

Foi explanado que a termorregulação do recém-nascido é diferente em relação ao adulto, pois a quantidade de calor ou frio que o mesmo suporta é relativamente menor, uma vez que sua composição física ainda não apresenta o tônus muscular necessário para produção de calor. Os alunos apresentaram às mães que uma das principais medidas para prevenção desse desequilíbrio hemodinâmico do RN é manter à criança sempre envolta por mantas e vestimentas que possam minimizar os efeitos da flutuação de calor para o ambiente. Os cuidados com a vestimenta ainda são de extrema relevância, necessitando de acessórios como gorros, meias, luvas e uma manta.

Através da boneca, foi demonstrada a melhor posição para o RN dormir, sendo esta a posição supina. De forma geral as mães discordaram quanto à posição supina, devido ao falecimento súbito de um bebê na comunidade que estava nessa posição; uma delas afirmou que continuaria a utilizar a posição lateralizada por acreditar ser mais segura e que garantiria que o bebê não tombaria. Ressaltou-se também a necessidade de retirar objetos do berço devido ao risco de a criança puxar para a face e se sufocar, além de dormir no berço e não junto com os pais, com o objetivo de evitar que os mesmos sufoquem a criança. Uma das mães discordou, afirmando que o hábito de dormir todos juntos fortalece a união familiar.

A posição supina previne que ocorra com o RN a síndrome da morte súbita do lactente (SMSL), tida como a ocorrência inesperada de óbito entre menores de um ano, sem causa aparente e que não pode ser explicada pelas informações coletadas e nem pela realização de exame pós-morte. Acredita-se, embora sem dados conclusivos, que a incidência seja maior em países de baixa renda devido à pouca familiaridade das mães com assuntos voltados à gestação e ao puerpério. Visto isso, há a necessidade dos profissionais de saúde repassarem, insistirem e incentivarem as mães a colocarem os recém-nascidos para dormir nessa posição. Isto porque se trata de uma medida simples, de baixo custo, de fácil aplicação e com resultado comprovadamente eficaz (CESAR et al., 2018).

Ao final da ação, foi realizado um momento de reflexão sobre a singularidade de cada indivíduo na sua infância e como educar seus filhos em relação ao preconceito e julgamento Pesquisa e Extensão 
com quem possui características diferentes daquelas do meio em que estão acostumados. Como por exemplo: a cor, religião, transtornos mentais, classe social e outras inúmeras formas de preconceito, na qual muitas crianças apenas reproduzem nas escolas aquilo que veem no comportamento daqueles que a cercam. Duas mães relataram que seus filhos já sofreram preconceito na escola; um devido à cor e o outro por apresentar transtorno do espectro autista.

\section{CONSIDERAÇÕES FINAIS}

Diante do exposto, a ação facilitou o processo dinâmico com o público, instigando a obter conhecimento adequado sobre a temática, além de levar ensinamentos sobre intervenções corretas que poderão ser necessárias. A ação serviu para destacar o papel educativo da enfermagem como formadora da autonomia de seus clientes, levando-os a reconhecerem o problema e realizarem domesticamente a prática ideal, de modo a prevenir situações adversas.

Os acadêmicos puderam conhecer os aspectos que podem contribuir negativa ou positivamente a saúde das crianças. Tais aspectos são indicadores a serem trabalhados pelo enfermeiro para orientar suas ações de cuidado, com o objetivo de conscientizar sobre a relevância da prática do cuidar da criança. Ao fazê-lo, são necessárias políticas que foquem na formação profissional, na orientação familiar e nos estímulos de mudanças primordiais que venham beneficiar a criança e a família que está inserida.

\section{REFERÊNCIAS}

AMADOR, B. M. Guia de cuidados básicos com recém-nascido na Estratégia Saúde da Família. Monografia (Especialização em Linhas de Cuidado em Enfermagem - em Saúde Materna, Neonatal e do Lactente) Universidade Federal de Santa Catarina. Florianópolis, p.41. 2014.

ANTUNES, L. S.; et al. Amamentação natural como fonte de prevenção em saúde. Rev. Ciência e Saúde Coletiva, n.1, vol.13, p. 103-109, 2008.

ARAÚJO, B. B. M.; RODRIGUES, B. M. R. D.; PACHECO, S. T. A. A promoção do cuidado materno ao neonato prematuro: a perspectiva da educação problematizadora em saúde. Rev. Enferm. UERJ, Rio de Janeiro, n.1, v.23, p.121-131, 2015.

CESAR, J. A.; et al. Intenção das mães em colocar o bebê para dormir em decúbito dorsal: um estudo de base populacional. Rev. Ciência \& Saúde Coletiva, n.2, v.23, p.501-508, 2018.

FARINHA, A. L.; RIVAS, C. M. F.; SOCCOL, K. L. S. Estratégia de ensino-aprendizagem da manobra de heimlich para gestantes: relato de experiência. Rev. Disciplinarum Scientia, n.1, v.22, p.59-66, 2021. 
FERREIRA, T. N.; et al. A importância da participação paterna durante o pré-natal: percepção da gestante e do pai no município de Cáceres-MT. Rev. Eletr. Gestão \& Saúde, n. 2, v.5, p.337-345, 2014.

GOMES, A. L. M. et al. Conhecimentos de familiares sobre os cuidados com recémnascidos. Revista da Rede de Enfermagem do Nordeste, n.15, v.16, p.258-265, 2015.

HOFFMANN, M. V. Conhecimento da família acerca da saúde das crianças de 1 a 5 anos em uma comunidade ribeirinha: subsídios para a enfermagem pediátrica. Rev. Esc Anna Nery, n.4, v13, p.750-756, 2009. 